\title{
胁 \\ NeuroRehab \\ News \\ Consejos de Neurociencias para Favorecer el Aprendizaje Motor en el Cerebro Dañado
}

Neuro-rehabilitación y Neuro-regeneración

\section{Infografía}

ใै?

NeuroRehab

\section{Consejos de Neurociencias para Favorecer el Aprendizaje Motor en la Neurorehabilitación}

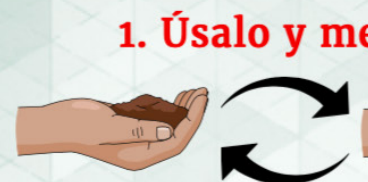

2. Úsalo o lo perderás

Dos consejos que siguen un mismo principio: El entrenamiento que impulsa una función cerebral, mejora dicha función, sin embargo, si no se impulsa una función, ésta se degrada.

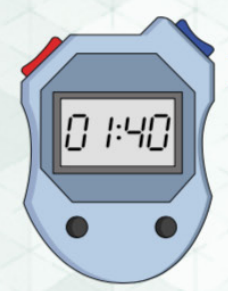

3. Cuanto antes

El momento en el que se realiza el ejercicio es vital para favorecer el aprendizaje

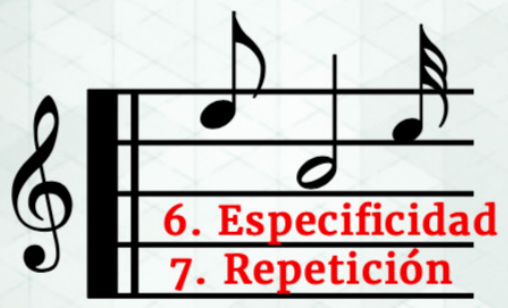

Los cambios que produce el entrenamiento en el cerebro se producen de una forma muy específica, según el entrenamiento que realicemos. Y esos cambios dependen también del número de veces que realicemos el entrenamiento

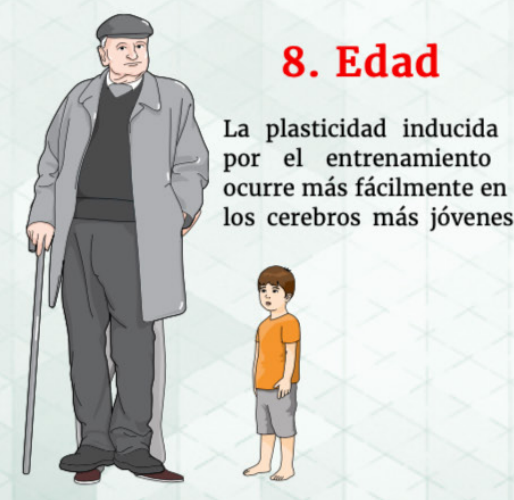

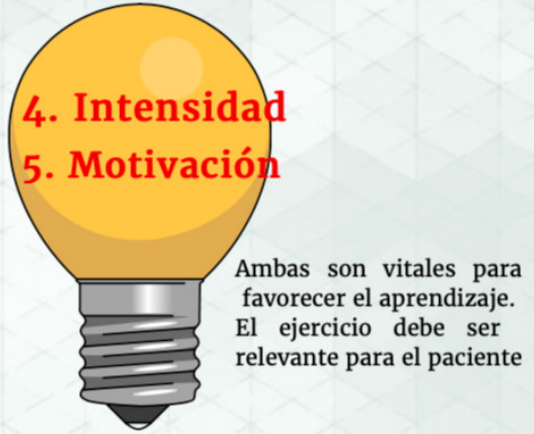

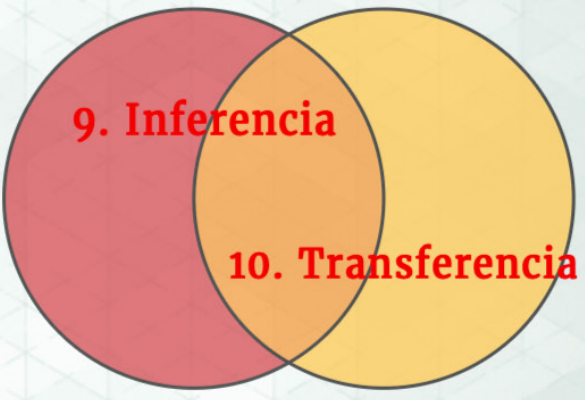

La plasticidad que produce un entrenamiento puede mejorar la adquisición de movimientos similares a ese entrenamiento. Pero esta plasticidad puede interferir con la adquisición de otros movimientos diferentes.
La investigación en neurociencias ha logrado avances significativos en la comprensión de la plasticidad neuronal dependiente de la experiencia, pero estamos lejos aún de comprender los circuitos cerebrales al nivel necesario para restaurar de la forma adecuada una función perdida creando conexiones neuronales. Pero afortunadamente, hay otra forma de crear conexiones neuronales funcionalmente apropiadas. Podemos aprovechar la forma en que el cerebro normalmente hace esto, es decir, a través del aprendizaje.

Estos hallazgos comienzan a integrarse con la investigación sobre los efectos degenerativos y regenerativos del daño cerebral. De esta manera se integra y combina la investigación básica y clínica para intentar favorecer el aprendizaje de una forma más eficiente, en los casos donde hay daño cerebral.

Los 10 principios de la plasticidad cerebral dependiente de la experiencia, con interés desde la neuro-rehabilitación, se resumen en los siguientes apartados:

1.Úsalo o lo perderás: La imposibilidad de conducir funciones cerebrales de una región específica puede conducir a que las neuronas de dicha zona sufran una degradación funcional.

2. Úsalo y mejóralo: Mediante el mismo principio que en el apartado

"La plasticidad neuronal es la base para aprender en el cerebro sano y para volver a aprender en el cerebro dañado" 
anterior, el entrenamiento que impulsa una función cerebral de una región específica puede conducir a una mejora de las neuronas de esa zona, mejorando la función.

3. La especificidad en el entrenamiento importa: La naturaleza de la experiencia de entrenamiento dicta la naturaleza de la plasticidad, es decir, los cambios que produce el entrenamiento en el cerebro se producen de una forma muy específica según el entrenamiento que realicemos.

4. La repetición importa: Un componente importante para la inducción de plasticidad es la repetición. Como al recorrer un camino en un bosque numerosas veces, al final queda una senda.

5. La intensidad importa: Otro componente para la inducción de plasticidad es la intensidad de entrenamiento.

6. El momento importa: Diferentes formas de plasticidad ocurren en diferentes momentos durante el entrenamiento.

7. La motivación y la atención importa: La experiencia de entrenamiento debe ser lo suficientemente destacada como para inducir plasticidad, los estímulos deben ser relevantes para el paciente.

8. La edad importa: La plasticidad inducida por el entrenamiento ocurre más fácilmente en los cerebros más jóvenes.
"El entrenamiento de rehabilitación es una herramienta para mejorar la reorganización cerebral y el resultado funcional "

9. Transferencia: La plasticidad en respuesta a un entrenamiento puede mejorar la adquisición de comportamientos similares a ese entrenamiento, es decir, con un entrenamiento específico, puede mejorar el aprendizaje de movimientos parecidos .

10. Interferencia: Aquí encontramos lo contrario, donde la plasticidad en respuesta a una experiencia puede interferir con la adquisición de otros comportamientos. Esto ocurre cuando es diferente el entrenamiento y los otros movimientos.

Aunque un gran cuerpo de evidencia apoya el entrenamiento y el aprendizaje como motores de la recuperación funcional en pacientes con patología, todavía hay muchos aspectos del entrenamiento poco conocidos que probablemente sean críticos para optimizar la rehabilitación.

\section{Sobre este artículo:}

Fuente /s:

- Kleim JA, Jones TA. Principles of experience-dependent neural plasticity: implications for rehabilitation after brain damage. J Speech Lang Hear Res. 2008 Feb;51(1):S225-39. doi: 10.1044/1092-4388(2008/018).

Fuente de las Imágenes: Imagen de NeuroRehabnews.com con fines únicamente ilustrativos.

Para citar este artículo: Delicado-Miralles, M. Consejos de neurociencias para favorecer el aprendizaje motor en el cerebro dañado. NeuroRehab News 2019 feb; 3 (1): e0049.

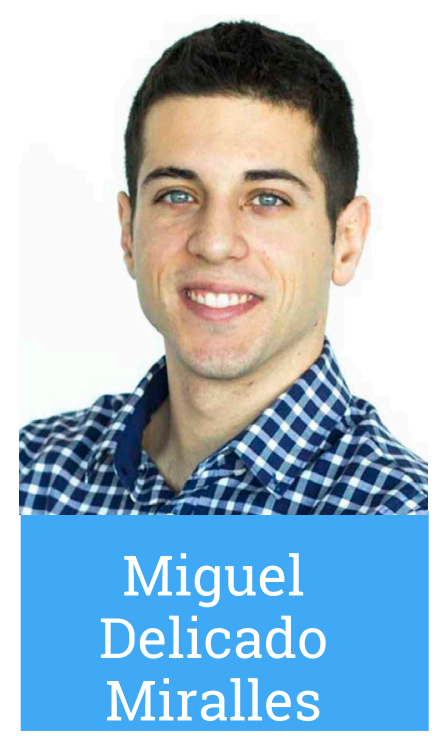

